Research Article

\title{
Determination of Chemical Composition of Essential Oils Extracted from Conventional and Organically grown Basil (Ocimum Basilicum) from Different Geographical Regions
}

\author{
Riaz Shah ${ }^{1 *}$, Shaikha Hilal Al Ismaili², Sheikha S. Al-Siaby ${ }^{1}$, Amal Mohammed Al Nasiri², Thuraiya \\ Hafidh Al Maskari ${ }^{2}$, Jamal AlSabahi ${ }^{3}$ and Huda Al-Ruqaishi ${ }^{3}$
}

${ }^{1}$ College of Agricultural and Marine Sciences, Sultan Qaboos University, Al-Khoud-123, Oman, Muscat, Sultanate of Oman; ${ }^{2}$ College of Science, Sultan Qaboos University, Sultanate of Oman; ${ }^{3}$ Central analytical laboratory, College of Agricultural and Marine Sciences, Sultan Qaboos University, Sultanate of Oman.

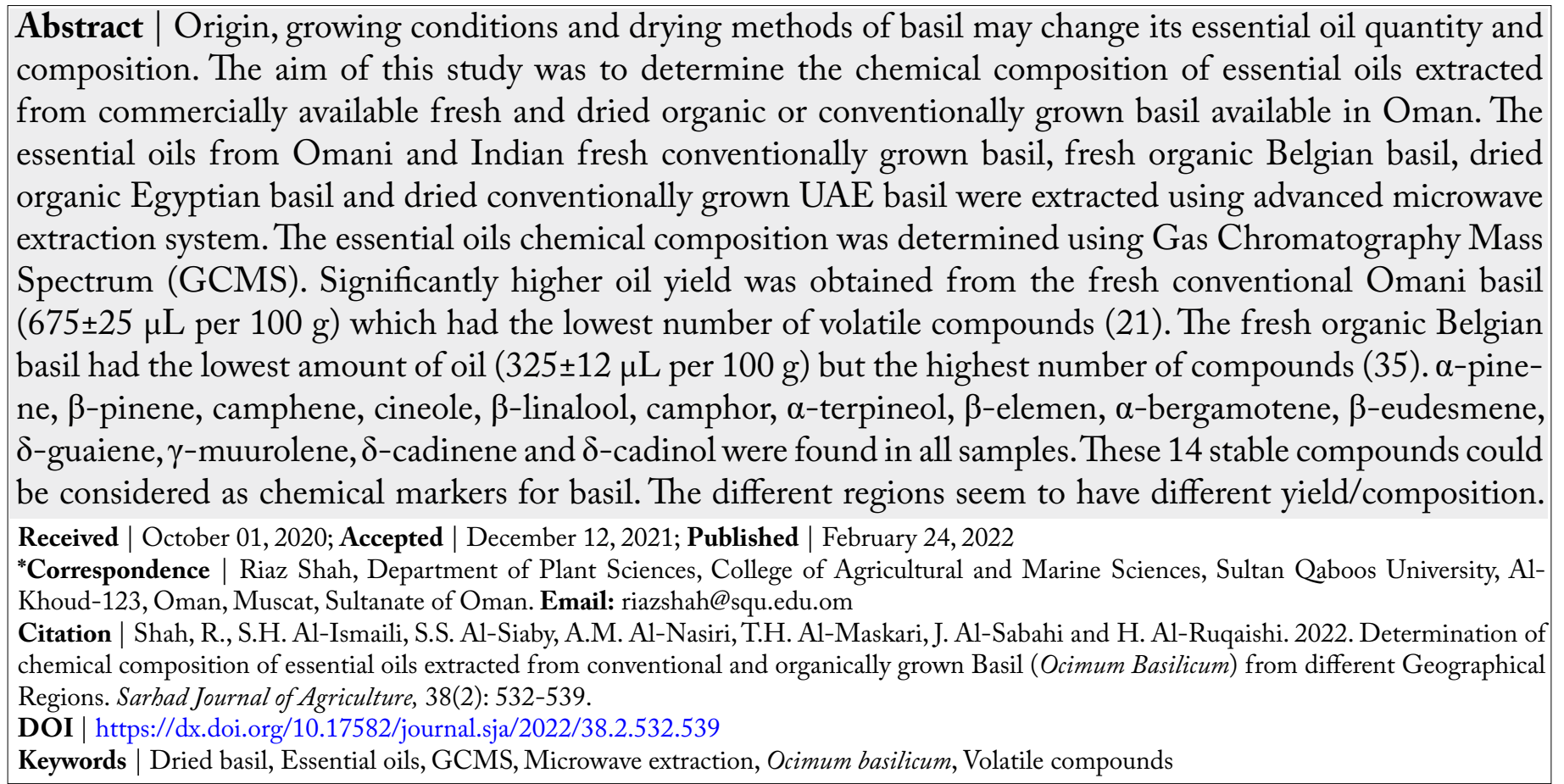

\section{Introduction}

$\mathrm{P}$ lants are used as food additives, pharmaceuticals, fragrances and for herbal medicine purposes (Lucchesi et al., 2004; Politeo et al., 2007). Basil Ocimum basilicum (Lamiaceae) called Rehan in Arabic, is one of the aromatic herbs that are grown and used in most of the countries around the world (Politeo et al., 2007; Hanif et al., 2011). Basil leaves have distinctive aroma and both fresh and dried forms are used as a spice in meals. Fresh or dry basil are used as medic- inal herbs to treat some diseases such as headaches, constipation, inflammation and coughs (Simon et al., 1999; Opalchenova and Obreshkova, 2003). Moreover, basil is believed to have antimicrobial, antioxidant and anticarcinogenic activity (Nurzynska-Wierdak, 2013).

The presence of essential oils and their composition determines the specific aroma of a plant. The presence of essential oils present in basil aerial parts contain 1,8-cineole, linalool, methyl cinnamate and methyl 
chavicol which are attributed to its aroma (Klimánková et al., 2008; Nurzynska-Wierdak, 2013; Bufalo et al., 2015).

Several techniques have been developed to extract the EO and volatile compounds from plants (Lucchesi et al., 2004). Traditional extraction methods have some difficulties and compounds like monoterpenes can undergo chemical changes or most volatile compounds can be lost during the solvent removal step (Lucchesi et al., 2004; Klimánková et al., 2008). A microwave extraction system was used in this study which heats the solvents and partition analytes from the sample matrix. This process uses least amount of solvent and there is no solvent removal step. Microwave-assisted extraction technology has been used to extract compounds from plants which facilitates the diffusion of the compounds into the extracting solvent (Flórez et al., 2015; Adetunji et al., 2017).

Composition of essential oil is influenced by many factors including the cultivation practices, cultivars, origin of the plant, colour of leaves, and the drying and extraction methods (Hussain et al., 2008; Bufalo et al., 2015). Geographical origins in particular affect compositions of essential oil. There are few studies that compare composition of essential oils extracted from commercially available fresh and dried, and organic and conventional basil. This study determines the essential oil volatile chemicals composition extracted from basil of different origin, state (fresh or dried) and growing conditions (organic or conventional) available in Oman using Gas Chromatograph Mass Spectrometer (GCMS).

\section{Materials and Methods}

\section{Plant material}

Intact plant in pots of conventional Omani and Indian basil and organic basil imported from Belgium (Vegobel) were purchased from a local market in AlKhoud, Oman. Pre-packaged (dried) conventional basil imported from United Arab Emirates (UAE) (Bayara) and organic basil originating from Egypt were also purchased from local market.

\section{Essential oils extraction}

Fresh Omani, Indian and Organic basil leaves (100 g) were placed in the microwave container to which distilled water $(2.5 \mathrm{~mL})$ was added before putting in the Milestone's Ethos X microwave extraction system
(Milestone, Italy) for $30 \mathrm{~min}$ at $280 \mathrm{~W}$. Dried basil $(100 \mathrm{~g})$, both conventional and organic, with distilled water $(2.5 \mathrm{~L})$ was kept in the microwave extraction system for $30 \mathrm{~min}$ at $280 \mathrm{~W}$. Water is a preferred solvent because it is safe and inexpensive. The extracted essential oil was collected, measured and stored at 4 ${ }^{\circ} \mathrm{C}$ until injection into GCMS. The volume of collected oil was then converted to mass using the known density of basil $\left(0.957 \mathrm{~g} / \mathrm{ml}\right.$ at $\left.25{ }^{\circ} \mathrm{C}\right)$. The yield of essential oil in percentage was calculated as follows:

Essential oil yield $(\%)=\frac{\text { Amount of essential oil }(g)}{\text { Weight of basil }(g)} \times 100$

\section{Essential oils composition by GCMS}

A drop of each of basil essential oil was added to 1 $\mathrm{mL}$ of hexane in separate vials and $1 \mu \mathrm{L}$ with split ratio of 100:1 was injected into GCMS. The chemical composition analysis was achieved using Perkin Elmer Clarus 600 GC System, Perkin Elmer Clarus 600C MS with quadrupole mass analyzer and Rtx5MS capillary column $(30 \mathrm{~m} \times 0.25 \mathrm{~mm}$ i.d.; film thickness $0.25 \mu \mathrm{m} ; 350^{\circ} \mathrm{C}$ maximum temperature). Injection temperature was set as $280^{\circ} \mathrm{C}$ and that of transfer line and ion source was $270{ }^{\circ} \mathrm{C}$. Helium (99.9999\% purity) was used as a carrier gas with constant flow rate of $1 \mathrm{~mL} / \mathrm{min}$. Ionization energy was 70 $\mathrm{eV}$, mass spectra scan range was 40-550 amu and 60 ${ }^{\circ} \mathrm{C}$ oven temperature programmed rate of $8{ }^{\circ} \mathrm{C}$ per min to $280{ }^{\circ} \mathrm{C}$ and $25 \mathrm{~min}$ hold. The run time was $53.5 \mathrm{~min}$. Components were identified using NIST 2011 v.2.3 and Wiley (9 $9^{\text {th }}$ edition) mass spectrum libraries.

Table 1: Yield of essential oil from different types of basil using advanced microwave extraction method.

\begin{tabular}{lll} 
Type of basil & $\begin{array}{l}\text { Volume }(\boldsymbol{\mu L}) \\
\text { per } \mathbf{1 0 0} \mathbf{g}\end{array}$ & Yield $(\% \mathbf{v} / \mathbf{w})$ \\
\hline Fresh conventional Indian basil & $475 \mathrm{c}$ & $0.47 \mathrm{c}$ \\
Fresh conventional Omani basil & $675 \mathrm{~d}$ & $0.67 \mathrm{~d}$ \\
Fresh organic Belgian basil & $325 \mathrm{a}$ & $0.32 \mathrm{a}$ \\
Dried conventional basil (UAE) & $375 \mathrm{~b}$ & $0.37 \mathrm{~b}$ \\
Dried organic basil (Egypt) & $388 \mathrm{~b}$ & $0.38 \mathrm{~b}$
\end{tabular}

\section{Results and Discussion}

\section{Yield of essential oil}

There was significant difference $(\mathrm{F}=35.9 ; \mathrm{df}=4,9$; $\mathrm{p}<0.001)$ in the amount of essential oil extracted from different samples (Table 1). The highest yield of essential oils was obtained from the conventional 
fresh Omani basil $(675 \pm 25 \mu \mathrm{L})$ and the lowest from the organic fresh basil $(325 \pm 12 \mu \mathrm{L})$. Dried conventional (UAE) and organic (Egypt) basil had similar oil yields.

\section{Essential oil composition}

Essential oil composition of organic and conventional fresh and dried basil (O. basilicum L.) from different geographical sources was identified using GCMS. The relative content of each volatile component is expressed as a relative percentage (100\% is equivalent to the sum of all 42 detected compounds. A total of 42 compounds were detected in the essential oils from all the basil samples of which 38 were identified; 35 from fresh organic Belgian basil, 28 from dried organic basil (Egypt), 28 from dried conventional basil (UAE), 24 from fresh conventional Indian basil and 21 from fresh conventional Omani basil (Table 2 and Figure 2). The detected compounds included sesquiterpene hydrocarbons ( $\alpha$-bergamotene, $\beta$-caryofyllen, $\alpha$-humulene), benzenoid compounds (methyl chavicol), monoterpene hydrocarbons ( $\alpha$-pinene, etc.) and oxygenated products (1,8-cineole, linalool, and camphor). Among the total volatile compounds 14 were common in all the basil types, which were $\alpha$-pinene, camphene, $\beta$-pinene, cineole, $\beta$-linalool, camphor, $\alpha$-terpineol, $\beta$-elemen, $\alpha$-bergamotene, $\beta$-eudesmene, $\delta$-guaiene, $\gamma$-muurolene, $\delta$-cadinene and $\delta$-cadinol. $\beta$-linalool was the main compound found in the essential oils of all basil types used (31.74-80.47\%) except for dried conventional basil imported from UAE where it was the second most abundant after $\alpha$-terpineol.

The specific aroma and flavour of plants depends on the presence and composition of essential oils. Different factors affect the essential oil yield and its chemical composition. These factors include different cultivars and their growing conditions (conventional vs organic) and, harvesting, drying and extraction techniques (Merk et al., 1988; Muzika et al., 1989; Klimánková et al., 2008; Lee et al., 2005).

The essential oil yield of $475-675 \mu \mathrm{L}$ per $100 \mathrm{~g}$ in our study is comparably to $450-1110 \mu \mathrm{L}$ per $100 \mathrm{~g}$ extracted from different cultivars of fresh conventionally grown basil. However, a volume of $325 \mu \mathrm{L}$ per 100 $\mathrm{g}$ reported from fresh organic Belgian basil is lower than the $400-1100 \mu \mathrm{L}$ per $100 \mathrm{~g}$ reported for the same cultivars of fresh organic basil (Klimánková et al., 2008; Bufalo et al., 2015). The reason for the lower quantity of $\mathrm{EO}$ from fresh organic basil in study may not be because of the growing conditions (conventional vs organic) but because of difference in cultivar and the long time spent between transit and sample analysis. The fresh Indian basil also had lower yield of EO because of the same reason. The essential oil components are volatile and increase in the time between harvesting/dispatch and analysis had decreased the yield of EO (Klimánková et al., 2008). Moreover, the growth conditions during transit are also not optimal for the plant (when whole plants are shipped).

On other hand the drying process will also reduce the quantity and composition of EO. Various physicochemical processes, e.g. oxidation, evaporation, etc during the drying change the aromatic volatile compounds influencing the aroma and the quality of the dried products (Jerković et al., 2001). In dried basil a decrease in sesquiterpene hydrocarbons, benzenoid compounds, and monoterpene hydrocarbons and increase in oxygenated products has been reported (Klimánková et al., 2008). The exact composition and drying techniques of the commercially-available dried basil used in our study were unknown and this might be the reason of varied composition (Chalchat and Özcan, 2008).

Direct comparison of fresh vs dry samples from different region, keeping in mind the available data, is not reliable because there are too many parameters to compare. We, therefore avoided to focus too much on this comparison, but focused more on the yield and composition.

Several studies were conducted to identify the chemical composition of basil from many regions of the world. The profile of $O$. basilicum oil determined in this study is almost similar to many studies (Klimánková et al., 2008; Zheljazkov et al., 2008; Chenni et al., 2016). One study on chemical composition of Omani basil indicated linalool (69.9\%) as the main compound while geraniol, 1,8-cineole, bergamotene and geranyl acetate were also found (Hanif et al., 2011). These values are similar to our findings and the variations could be contributed to the cultivar, extraction process (Clevenger type distillation apparatus) and the part of the plant used (whole plant with flowers). Linalool, 1,8-cineole and eugenol were also identified as dominant components in Egyptian basil oil (Ismail, 2006). The essential oil of a native northeast Indian O. basilicum had very high camphor (42.1\%) 
Table 2: Volatile compounds identified in different basil samples determined by GC-MS and expressed as a relative percentage. 100\% is equivalent to the sum of all identified compounds for that sample.

S.

No.

\section{Name}

$1 \quad \alpha$-Pinene

2 Camphene

3 2,4- Thujadiene

$4 \quad \beta$-Pinene

5 Octamethyl cyclotetrasiloxane

6 4-Carene

7 1,8-Cineole

$8 \gamma$-Terpinene

$9 \beta$-Ocimene

10 Fenchone

$11 \beta$-Linalool

12 Camphor

13 Isoborneol

14 Terpinen-4-ol

$15 \alpha$-Terpineol

16 Tarragon

17 Estragole (methyl chavicol)

18 Geraniol

19 Bornyl acetate

20 Unidentified

21 Copaene

$22 \beta$-Elemen

23 Caryophyllene

24 Methyl eugenol

$25 \alpha$-Bergamotene

26 (E)- $\beta$-Farnesene

27 Humulene

$28 \alpha$-Caryophyllene

$29 \beta$-Gurjunene

30 Unidentified

31 Germacrene D

$32 \beta$-Eudesmene

33 Eremophilene

$34 \delta$-Guaiene

$35 \gamma$-Muurolene

$36 \delta$-Cadinene

37 Unidentified

38 Unidentified

39 Spathulenol

40 Caryophyllene oxide

41 Unidentified

$42 \delta$-Cadinol

\section{Conventional} $\mathrm{t}_{\mathrm{R}}$ (minutes) Fresh (Omani) Fresh (Indian) Dried (UAE) Fresh (Belgian) Dried (Egypt)

$\begin{array}{llllll}4.19 & 1.36 & 0.76 & 1.66 & 9.40 & 6.78\end{array}$

4.43

$0.08 \quad 0.06$

4.52

4.86

$--$

0.83

$--$

0.83

$--$

$-0.28$

5.43

5.72

6.40

6.46

5.49

--

0.20

$--$

6.52

--

$--$

80.47

0.06

6.88

7.69

0.48

75.14

0.50

--

8.10

$--$

8.43

8.72

--

8.96

9.26

10.06

11.17

11.57

11.81

12.10

12.34

12.44

12.52

12.79

12.87

12.93

13.12

13.21

13.30

13.44

13.57

13.70

13.82

13.95

14.55

14.71

14.77

15.21

15.55

15.61

$\begin{array}{lll}1.66 & 9.40 & 6.78 \\ 0.08 & 0.31 & 0.30\end{array}$

$-$

0.49

0.15

0.13

0.95

0.13

0.83

0.12

0.19

0.20

0.30

5.93

5.60

8.55

0.11

$--$

0.30

0.09

13.12

31.75

--

0.47

1.36

46.43

0.89

0.08

0.27

0.28

0.15

0.26

0.52

0.57

0.45

0.56

71.58

0.62

0.79

$--$

0.74

$--$

0.16

$--$

5.77

$\begin{array}{ll}-- & 7.26\end{array}$

4.81

7.11

$--$

$--$

0.37

2.88

1.40

$\begin{array}{llll}-- & - & & 0.06\end{array}$

0.32

1.31

$--$

0.19

$--$

3.98

0.04

0.16

0.13

0.14

$--$

$--$

2.01

$--$

2.49

0.05

0.07

0.40

3.90

1.06

0.72

$--$

1.13

$\begin{array}{ll}-- & 10.08\end{array}$

$1.19 \quad 5.14$

3.97

$--$

$--$

0.05

0.08

0.04

0.35

$--$$$
--
$$

$--$

$--$

--

0.33

$--$

0.26

$--$

0.23

0.29

0.12

0.27

0.09

$\begin{array}{ll}-- & 0.03\end{array}$

1.39

$--$

1.75

0.34

0.15

$\begin{array}{ll}-- & 2.19\end{array}$

0.14

0.56

0.75

1.17

0.31

0.72

1.97

0.40

0.18

0.12

0.40

$\begin{array}{ll}-- & 0.40\end{array}$

$\begin{array}{ll}-- & 0.31\end{array}$

0.80

1.28

0.98

6.97

1.05

0.77

Basil type

6.97

June 2022 | Volume 38 | Issue 2 | Page 535 
(Purkayastha and Nath, 2006). The main constituents of the basil oil from French Polynesia were (E)-methyl cinnamate $(62.3 \%)$ and $(Z)$-methyl cinnamate (8.6\%) (Adam et al., 2009). Methyl chavicol (37.643.0\%) and linalool (28.9-33.4\%) were found as the major compounds in the $\mathrm{EO}$ in two varieties of O. basilicum from Iran while another variety was rich in geranyl acetate (45.6\%) but low in linalool (25.6\%) (Safari et al., 2014). Different cultivars may show a similar pattern of volatile compounds but the relative amount of major components, for example, linalool, eugenol, 1,8-cineole, and bergamotene, etc usually differ (Klimánková et al., 2008).

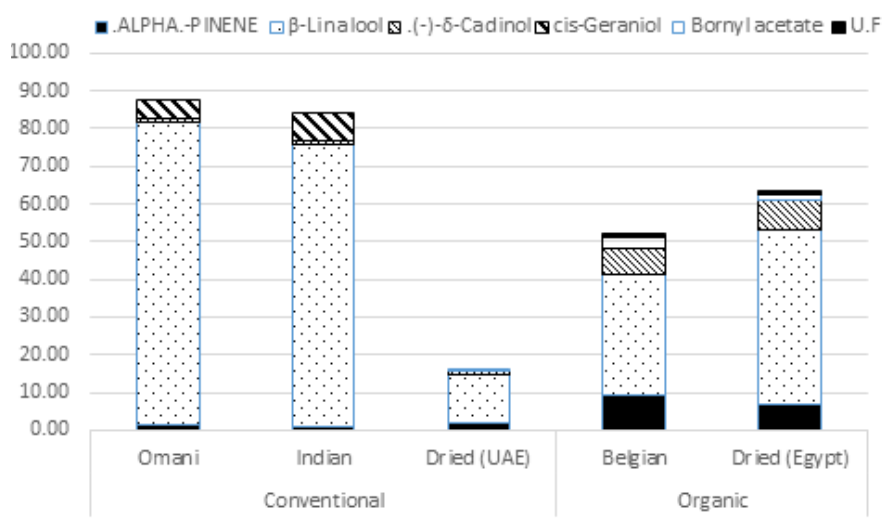

Figure 1: Comparison of some compounds in conventionally grown and organic basil.

The different volatile compounds found in essential oil of basil have different properties. Many authors reported $\beta$-linalool as the main component of basil essential oil in previous studies (Mondello et al., 2002; Telci et al., 2006; Hussain et al., 2008; Bufalo et al., 2015). European basil oil especially Bulgarian basil oil is considered as a high quality essential oil due to higher linalool contents (71.4\%) (Jirovetz et al., 2001; Sifola and Barbieri, 2006). Linalool is a terpene alcohol found in many spices and flowers and has anti-inflammatory, antibacterial, antifungal and antiviral properties (Politeo et al., 2007). Linalool due to its pleasant scent has been used in perfumed hygiene products and cleaning agents including soaps, detergents, shampoos, and lotions.

Essential oils extracted from aromatic plants has a monoterpene called geraniol. Geraniol has been found effective against breast, liver, colon, prostate, pancreatic, skin, lung and kidney cancers (Koziol et al., 2015; Cho et al., 2016). Geraniol is classified as safe food additive by the Food and Drug Administration (FDA) of the United States. Geraniol is also approved for use within allergenic epicutaneous patch tests used as an aid in the diagnosis of allergic contact dermatitis (ACD).

$\beta$-elemene belongs to the class of organic compounds known as elemane sesquiterpenoids which has antibacterial properties (Noriega et al., 2019). Methyl chavicol (estragole) have shown antioxidant and antilipase activities which may make it useful in the treatment of diseases (Panten and Surburg, 2018). Isobornyl acetate is used in perfuming soap, bath products, and air fresheners, and production of camphor (Purkayastha and Nath, 2006).

A strong negative correlation $\left(r=-0.88 ; \mathrm{r}^{2}=0.77 ; \mathrm{p}\right.$ $=0.04$ ) was observed between the amount of oils extracted and the number of compounds detected. The fresh organic basil had yielded the least oil but had the highest number of compounds. Although the EO yield of the fresh organic basil was very low due to long transit and poor growth conditions the compounds present in the EO did not deteriorate and we were able to extract them. The essential oil extracted from conventional and organic basil did not differ much in terms of profile but composition did differ. Organic basil had much higher amount of $\alpha$-pinene and $\delta$-cadinol compared to conventional basil while $\beta$-linalool was high in conventional basil (Figure 1). Some additional compounds were detected only in organic basil (Egyptian and Belgian) although in very low percentages (0.12-2.87\%). Examples of these compounds were spathulenol, 2,4-Thujadiene, caryophyllene oxide, octamethyl cyclotetrasiloxane, bornyl acetate, isoborneol and caryophyllene. Methyl eugenol was found only in organic fresh Belgian basil samples. We did not detect methyl chavicol in fresh organic basil and a significantly lower level of methyl chavicol has been reported in one organically grown cultivar compared to the same cultivar grown conventionally (Klimánková et al., 2008). Some reports demonstrated that organic and conventional fertilizers or growing conditions did not modify the profile composition of sweet basil essential oils but the relative percentages of volatile compounds were found different among cultivars (Klimánková et al., 2008; Bufalo et al., 2015).

The difference in the amounts and the types of volatile compounds from basil from different countries in current study may be due to genetic factors, local environmental conditions, plant nutrition and different genotype (cultivars) (Klimánková et al., 2008). Apart from 

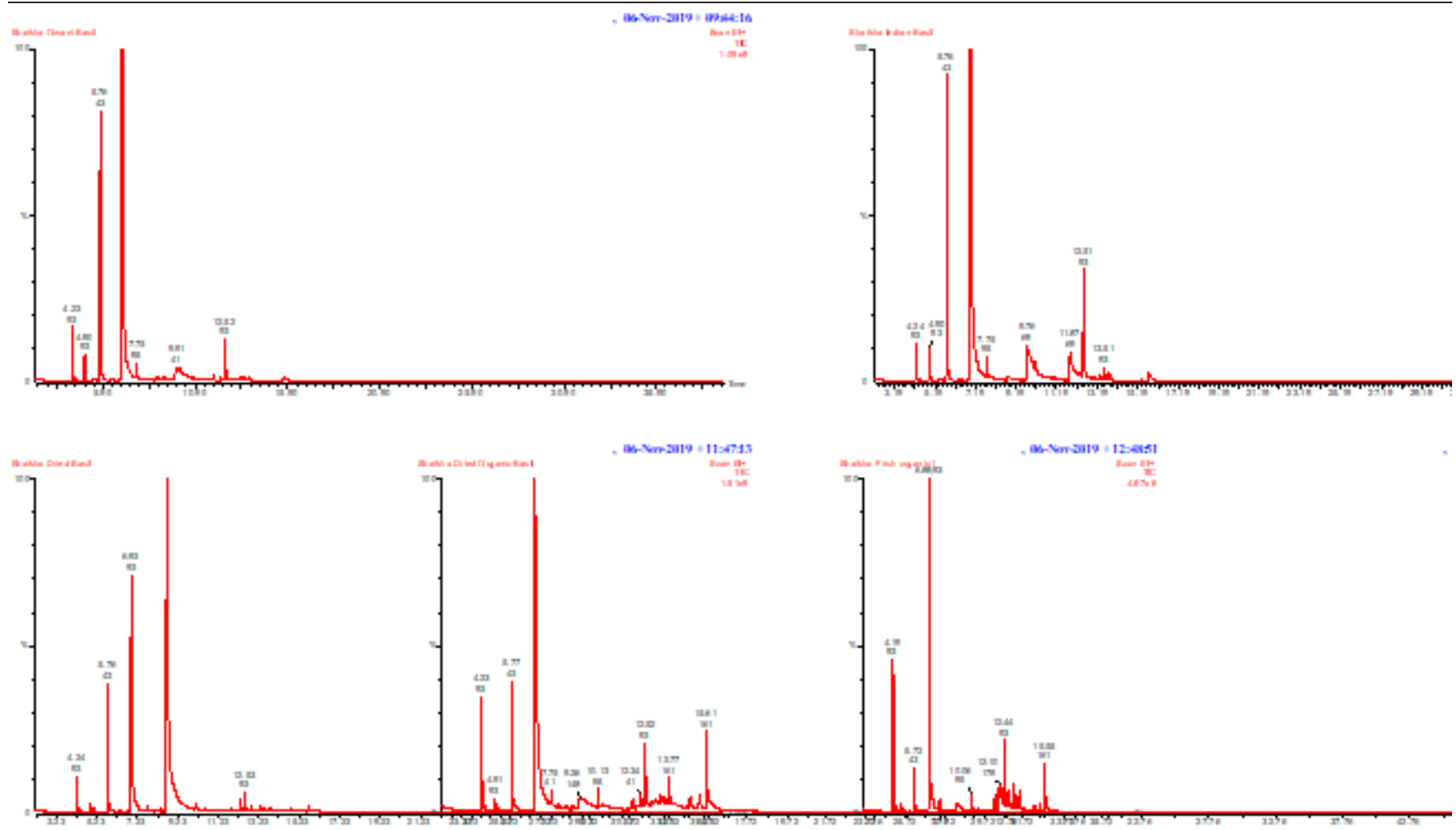

Figure 2: Chromatograms of volatile compounds detected by GCMS in the essential oils extracted from Ocimum basilicum.

many factors, linalool, 1,8-cineole, methyl cinnamate, and methyl chavicol are the main volatile compounds responsible for the typical basil aroma (Lee et al., 2005). Based on essential oil chemotypes classification by Lawrence (1988), Omani and Indian fresh basil was linalool-rich, Belgian organic basil was methyl eugenol-rich, Egyptian dried basil was methyl chavicol-rich (Lawrence, 1988). UAE dried basil was terpineol-rich.

\section{Conclusions and Recommendations}

The essential oil yield and component profiles were seen to be responsive to the plant origin and/or growing environment. A total of 14 volatile compounds were common in all the basil types; $\alpha$-pinene, $\beta$-pinene, camphene, cineole, $\beta$-linalool, camphor, $\alpha$-terpineol, $\beta$-elemen, $\alpha$-bergamotene, $\beta$-eudesmene, $\delta$-guaiene, $\gamma$-muurolene, $\delta$-cadinene and $\delta$-cadinol. $\beta$-linalool was the main compound identified in the essential oils of analyzed basil types used (31.74$80.47 \%)$. Higher number of volatile compounds was detected in organic compared to commercially grown basil.

\section{Novelty Statement}

The fourteen stable compounds identified from basil could be considered as chemical markers for basil. Higher number of volatile compounds were detected in organic compared to commercially grown basil.

\section{Authors' Contributions}

Riaz Shah: Prepared and edited the manuscript.

Shaikha Hilal Al-Ismaili, Sheikha S. Al-Siaby, Amal Mohammed Al-Nasiri and Thuraiya Hafidh Al-Maskari: Arranged and prepared samples, extracted essential oils and conducted GCMS analysis. Jamal Al-Sabahi and Huda Al-Ruqaishi: Helped in GCMS analysis and requisition relevant data.

Conflict of interest

The authors have declared no conflict of interest.

\section{References}

Adam, F., I. Vahirua-Lechat, E. Deslandes, J.M. Bessiere and C. Menut. 2009. Aromatic Plants of French Polynesia. III. Constituents of the Essential Oil of Leaves of Ocimum basilicum L. J. Essent. Oil Res., 21(3): 237-240. https:// doi.org/10.1080/10412905.2009.9700158

Adetunji,L.R.,A.Adekunle, V.Orsat and V.Raghavan. 2017. Advances in the pectin production process using novel extraction techniques: $\mathrm{A}$ 
review. Food Hydrocoll., 62: 239-250. https:// doi.org/10.1016/j.foodhyd.2016.08.015

Bufalo, J., C.L. Cantrell, T. Astatkie, V.D. Zheljazkov and A. Gawde. 2015. Organic versus conventional fertilization effects on sweet basil (Ocimum basilicum L.) growth in a greenhouse system. Ind. Crops Prod., 74: 249-254. https:// doi.org/10.1016/j.indcrop.2015.04.032

Chalchat, J.C. and M.M. Özcan. 2008. Comparative essential oil composition of flowers, leavesand stems of basil (Ocimum basilicum L.) used as herb. Food Chem., 110(2): 501-503. https:// doi.org/10.1016/j.foodchem.2008.02.018

Chenni, M., D. El-Abed, N. Rakotomanomana, X. Fernandez and F. Chemat. 2016. Comparative Study of Essential Oils Extracted from Egyptian Basil Leaves (Ocimum basilicum L.) Using Hydro-Distillation and Solvent-Free Microwave Extraction. Molecules, 21(1): 113. https:// doi.org/10.3390/molecules21010113

Cho, M., I. So, J.N. Chun and J.H. Jeon. 2016. The antitumor effects of geraniol: Modulation of cancer hallmark pathways (Review). Int. J. Oncol. 48(5): 1772-1782. https://doi.org/10.3892/ ijo.2016.3427

Flórez, N., E. Conde and H. Domínguez.2015.Microwave assisted water extraction of plant compounds. J. Chem. Technol. Biotechnol., 90(4): 590-607. https://doi.org/10.1002/jctb.4519

Hanif, M.A., M.Y. Al-Maskari, A. Al-Maskari, A. Al-Shukaili and A.Y. A1-Maskari. 2011. Essential oil composition, antimicrobial and antioxidant activities of unexplored Omani basil. J. Med. Plants Res., 5(5): 751-757.

Hussain, A.I., F. Anwar, S.T.H. Sherazi and R. Przybylski. 2008. Chemical composition, antioxidant and antimicrobial activities of basil (Ocimum basilicum) essential oils depends on seasonal variations. Food Chem., 108(3): 986-995. https://doi.org/10.1016/j.foodchem.2007.12.010

Ismail, M. 2006. Central Properties and Chemical Composition of Ocimum basilicum . Essential Oil. Pharm. Biol., 44(8): 619-626. https://doi. org/10.1080/13880200600897544

Jerković, I., J. Mastelić and M. Miloš. 2001. The effect of air-drying on glycosidically bound volatiles from seasonally collected origano (Origanum vulgare ssp. hirtum) from Croatia. Nahrung/Food, 45(1): 47-49. https://doi.org/10.1002/1521-
$3803(20010101) 45: 1<47:$ : A I D FOOD 47>3.0.CO;2-G

Jirovetz, L., G. Buchbauer, A. Stoyanova and A. Balinova. 2001. Analysis, Chemotype and Quality Control of the Essential Oil of a New Cultivated Basil (Ocimum basilicum L.) Plant from Bulgaria. Sci. Pharm., 69(1): 85-89. https://doi. org/10.3797/scipharm.aut-01-10

Klimánková, E., K. Holadová, J. Hajšlová, T. Čaj$\mathrm{ka}$ and J. Poustka. 2008. Aroma profiles of five basil (Ocimum basilicum L.) cultivars grown under conventional and organic conditions. Food Chem., 107(1): 464-472. https://doi. org/10.1016/j.foodchem.2007.07.062

Koziol, A., A. Stryjewska, T. Librowski, K. Salat and M. Gawel. 2015. An Overview of the Pharmacological Properties and Potential Applications of Natural Monoterpenes. Mini-Rev. Med. Chem., 14(14): 1156-1168. https://doi.or $\mathrm{g} / 10.2174 / 1389557514666141127145820$

Lawrence, B.M. 1988. A further examination of the variation of Ocimum basilicum L. In: B. M. Lawrence, B. D. Mookerjee and B.J.W., editor, Flavors and fragrances. Elsevier Sci. Publ. B.V., Amsterdam. pp. 161-170.

Lee, K.D., M.S. Yang and D.L. Smith. 2005. Fertilizer effect on the yield and terpene components from the flowerheads of Chrysanthemum boreale M. (Compositae). Agron. Sustain. Dev., 25(2): 205-211. https://doi.org/10.1051/ agro:2005022

Lucchesi, M.E., F. Chemat and J. Smadja. 2004. Solvent-free microwave extraction of essential oil from aromatic herbs: comparison with conventional hydro-distillation. J. Chromatogr. A 1043(2): 323-327. https://doi.org/10.1016/j. chroma.2004.05.083

Merk, L., M. Kloos, R. Schonwitz and H. Ziegler. 1988. Influence of various factors on quantitative composition of leaf monoterpenes of Picea abies (L.) Karst. Trees 2(1). https://doi. org/10.1007/BF00196979

Mondello, L., G. Zappia, A. Cotroneo, I. Bonaccorsi and J. Chowdhury. 2002. Studies on the essential oil-bearing plants of Bangladesh. Part VIII. Composition of some Ocimum oilso. basilicum L. var. purpurascens; O. sanctum L. green; O. sanctum L. purple; O. americanum L., citral type; O. americanum L., camphor type. Flavour Fragr. J. 17(5): 335-340. https://doi. org/10.1002/ff. 1108 
Muzika, R.M., K.S. Pregitzer and J.W. Hanover. 1989. Changes in terpene production following nitrogen fertilization of grand fir (Abies grandis (Doug1.) Lind1.) seedlings. Oecologia, 80(4): 485-489. https://doi.org/10.1007/BF00380070

Noriega, P., A. Guerrini, G. Sacchetti, A. Grandini and E. Ankuash. 2019. Chemical Composition and Biological Activity of Five Essential Oils from the Ecuadorian Amazon Rain Forest. Molecules, 24(8): 1637. https://doi. org/10.3390/molecules24081637

Nurzynska-Wierdak, R. 2013. Essential oil composition of sweet basil cultivars as affected by nitrogen and potassium fertilization. Turkish J. Agric. For. https://doi.org/10.3906/tar-120343

Opalchenova, G. and D. Obreshkova. 2003. Comparative studies on the activity of basil-an essential oil from Ocimum basilicum L.-against multidrug resistant clinical isolates of the genera Staphylococcus, Enterococcus and Pseudomonas by using different test methods. J. Microbiol. Method., 54(1): 105-110. https://doi. org/10.1016/S0167-7012(03)00012-5

Panten, J. and H. Surburg. 2018. Flavors and Fragrances. Ullmann's Encyclopedia of Industrial Chemistry. 7th ed. John Wiley \& Sons, New York

Politeo, O., M. Jukic and M. Milos. 2007. Chemical composition and antioxidant capacity of free volatile aglycones from basil (Ocimum basilicum L.) compared with its essential oil. Food Chem., 101(1): 379-385. https://doi.org/10.1016/j. foodchem.2006.01.045

Purkayastha, J. and S.C. Nath. 2006. Composition of the Camphor-rich Essential Oil of Ocimum basilicum L. Native to Northeast India. J. Essent. Oil Res., 18(3): 332-334. https://doi.org/ 10.1080/10412905.2006.9699104

Safari, D., M. Saeed and M.C. Hengameh. 2014. Essential oil composition of four Ocimum species and varieties growing in Iran. J. Essent. Oil Res., 26(4): 315-321. https://doi.org/10.1080/1 0412905.2014 .889048

Sifola, M.I. and G. Barbieri. 2006. Growth, yield and essential oil content of three cultivars of basil grown under different levels of nitrogen in the field. Sci. Hortic. (Amsterdam), 108(4): 408-413. https://doi.org/10.1016/j.scienta.2006.02.002

Simon, J.E., M.R. Morales, W.B. Phippen, R.F. Vieira and Z. Hao. 1999. Basil: a source of aroma compounds and a popular culinary and ornamental herb. Perspect. new Crop. new uses, 16: 499-505.

Telci, I., E. Bayram, G. Yilmaz and B. Avc1. 2006. Variability in essential oil composition of Turkish basils (Ocimum basilicum L.). Biochem. Syst. Ecol., 34(6): 489-497. https://doi. org/10.1016/j.bse.2006.01.009

Zheljazkov, V.D., A. Callahan and C.L. Cantrell. 2008. Yield and Oil Composition of 38 Basil (Ocimum basilicum L.) Accessions Grown in Mississippi. J. Agric. Food Chem., 56(1): 241245. https://doi.org/10.1021/jf072447y 